\title{
Refugee Resettlement in the U.S.: The Impact of Contextual Factors on Psychological Distress
}

\author{
Laura M. Ramzy ${ }^{1, *}$, Danielle M. Jackman ${ }^{2}$, Adam Soberay ${ }^{2}$, Jamie Pledger ${ }^{1}$ \\ ${ }^{1}$ Colorado Refugee Wellness Center, Aurora Mental Health Center, USA \\ ${ }^{2}$ Aurora Mental Health Center, Aurora Research Institute, USA
}

Copyright $\bigcirc 2017$ by authors, all rights reserved. Authors agree that this article remains permanently open access under the terms of the Creative Commons Attribution License 4.0 International License

\begin{abstract}
The purpose of the current study was to examine the contribution of behavioral health treatment and several contextual factors - employment, English language proficiency, family separation, and local family support -- to psychological distress among newly resettled refugees over one year. Pre- and post-data were collected between July 2014 and January 2016 at an integrated care refugee clinic located in the western United States. The sample $(N=77)$ consisted of a diverse group of refugees, most of whom recently arrived from Burma, Iraq, Bhutan, Democratic Republic of Congo, and Somalia. The Refugee Health Screener-15 (RHS-15) was used to measure psychological distress at the initial screening and at 12 months for refugees who indicated distress at baseline. Findings indicated a significant increase in psychological distress for those who were employed, and a significant decrease in distress for those with at least some English language proficiency and for those who have family residing in or near their country of origin. Research recommendations include using a larger sample size and more robust assessment tools to further understand the influence of family separation on psychological distress. Practice recommendations include providing advanced employment options and increasing host country language class access for newly arrived refugees.
\end{abstract}

Keywords Contextual Barriers, Mental Health, Psychological Distress, Refugees, Social Determinants, Community Health Care

\section{Introduction}

There has been exponential growth in the number of refugees, or individuals fleeing their home country for well-founded fear of persecution, across the world. In 2015, a record-breaking 134,044 refugees were resettled in developed countries [1]. The United States, in particular, is the world's leading nation for refugee resettlement, with over 2.5 million refugees having been resettled since 1975 $[1,2]$. Studies have demonstrated that refugees tend to experience high levels of psychological distress $[3,4,5,6]$, and, in turn, suffer from a disproportionately higher percentage of mental health problems [7, 8]. Given the current global refugee crisis and ensuing sociopolitical, emotional, and psychological consequences, it is critical for public health scholars and practitioners to understand the needs of this population.

Many refugees are exposed to significant rates of adverse and traumatic experiences, including persecution, exposure to war and violence, and losses of family members and friends $[8,9,10,11]$. As a result, refugees tend to suffer greater stress than non-refugee immigrants $[12,13]$, and may experience posttraumatic stress, symptoms of depression, long term fatigue, and anxiety [14, 15]. In addition, refugees face significant contextual barriers (e.g., economic struggles, family separation, and acculturation difficulties) during the resettlement process $[3,16,17,18]$. While many studies have assessed the effects of mental health treatment $[2,8,10,19,20]$ and contextual factors $[21,21,23]$ on refugees' psychological distress, less empirical work has been concentrated on the effects of contextual factors on psychological distress over time [24], which is the purpose of this study.

Bronfenbrenner's ecological model can serve as a framework to encapsulate the role of contextual barriers on refugees' psychological distress. Scholars argue that for those in public health, an ecological perspective provides a necessary understanding of systemic sources for resilience among trauma survivors [25, 26, 27]. The ecological model postulates that individuals do not develop in isolation, but rather, within multiple nested systems, and that each system is dynamic in its influence on other systems. The four main systems include: Microsystems, people and communities that are directly connected to the individual (e.g., family, school, community); Mesosystems, the interrelationships between or among microsystems; Exosystems, the connection of settings not directly involving yet still affecting the 
individual (e.g., public policy); and Macrosystems, the cultural values, belief systems, and social structures influencing the individual and surrounding environment.

The ecological framework has been used in studies to understand the experience and resiliency of refugees and others subject to community violence, trauma, and terrorism [26, 28, 29]. Given the multidimensional acculturation process occurring upon arrival to their host country, the emphasis of cultural values within the ecological model is especially important when considering the needs of recently resettled refugees. Using an ecological framework allows scholars to assess how contextual factors influence change in psychological distress over time, and is the key in ascertaining efficacious interventions to reduce distress and increase resources.

Previous studies have evidenced a growing concern on the impact of post-migration factors on refugees' mental health $[30,31]$. Three frequently endorsed contextual factors that have been shown to influence refugees' mental health are language acquisition and proficiency, family separation, and employment [23, 31, 32]. For example, Marshall and colleagues [23] examined prevalence, correlates, and comorbidity of mental health disorders for Cambodian refugees, and found that having poor English language proficiency was associated with higher rates of Post-traumatic Stress Disorder (PTSD) and depression. Similarly, post-migration difficulties, including communication problems and worries about separated family members, were found to uniquely contribute to depression, anxiety, and somatic-related symptoms for Burmese refugees in Australia [32]. Further, while unemployment has been well established as a risk factor for poor mental health among refugees [23, 24, 31], other scholars have recently suggested that gainful employment can also increase psychological distress for longer established refugees. One reason for this discrepancy could be that the phase of resettlement may moderate the relationship between contextual factors and mental health outcomes [24, 33, 34]. Bentley and colleagues [3] examined post-migration contextual barriers, such as separation from family, poverty, and employment status, as a moderator between pre-migration trauma and current mental health symptoms among Somali refugees. Findings revealed that while contextual barriers did not serve as a moderator when examining somatic, anxiety, or PTSD symptoms, they did significantly moderate the relationship between pre-migration trauma and depression symptoms for those exposed to low levels of trauma.

While these studies highlight the impact of contextual factors on psychological distress for refugees, few scholars have examined the significance of these factors over time. The lack of empirical, longitudinal research conducted with refugee populations may be partly due to the number of difficulties and complexities associated with studying an extremely vulnerable population [22], including language and cultural barriers and frequent relocation within the first year of resettlement. Indeed, recommendations within meta-analyses call scholars to contribute more empirical studies to the refugee mental health literature [20, 22]. In one within-group longitudinal study conducted by Goodkind and colleagues [7], English language proficiency, the development of social supports, and a community-based intervention targeting post-migration stressors were found to effectively reduce psychological distress for African refugees. In another longitudinal study assessing contextual factors (i.e., legal status, social support, separation from children, having a partner) among a group of asylum seekers in Ireland, securing legal status was most effective in improving mental health outcomes [35]. Despite these notable efforts, a marked deficiency of research exists with regard to examining the influence of contextual barriers on psychological distress for newly resettled refugees over time.

\section{Current Study}

The current study focused on the long term effects of four contextual factors on the psychological distress of newly arriving refugees: employment, English language proficiency, family separation, and local family support. Grounded in Bronfenbrenner's ecological model [27] and previous empirical findings, four hypotheses related to comparative analyses were tested:

Hypothesis 1: Psychological distress significantly increases over time among recently resettled refugees who are employed.

Hypothesis 2: Psychological distress significantly decreases over time among recently resettled refugees who have at least some English language proficiency.

Hypothesis 3: Psychological distress significantly increases over time among recently resettled refugees who are separated from family members.

Hypothesis 4: Psychological distress significantly decreases over time among recently resettled refugees who have local family support.

\section{Methods}

\section{Participants}

Participants $(N=77 ; 57.1 \%$ female $)$ were refugees who (a) arrived in the United States between July 2014 and January 2016; (b) completed a health screening at an integrated care refugee clinic post-arrival $\left(M_{\text {days }}=62.37\right.$, $S D=23.28)$; (c) were at least 18 years old $\left(M_{\text {age }}=36.75\right.$, $S D=13.25)$; and (d) scored "positive" during the initial health screening on the Refugee Health Screener-15 (RHS-15), indicating significant psychological distress. Participants were given the option to engage in short term behavioral health treatment at the integrated care clinic site 
or be referred to a long term mental health agency if clinically appropriate. This study focused on the pooled sample of participants, as there were no observable significant short term behavioral health treatment effects found on psychological distress.

Thirteen countries and 17 languages were represented in the sample, with English not being the primary language of any participant. Table 1 and 2 highlight the most commonly spoken languages and most common countries of origin of participants.

Table 1. Most Common Primary Languages of Study Participants $(N=$ 77)

\begin{tabular}{|c|c|c|}
\hline Primary Language & $n$ & $(\%)$ \\
\hline Arabic & 21 & $(27.3)$ \\
\hline Burmese & 15 & $(19.5)$ \\
\hline Swahili & 10 & $(13.0)$ \\
\hline Nepali & 8 & $(10.4)$ \\
\hline Farsi & 4 & $(5.1)$ \\
\hline Other languages & 19 & $(24.7)$ \\
\hline
\end{tabular}

Table 2. Most Common Countries of Origin of Study Participants $(N=$ 77)

\begin{tabular}{|c|c|c|}
\hline Primary Countries & $n$ & $(\%)$ \\
\hline Burma & 17 & $(22.1)$ \\
\hline Iraq & 17 & $(22.1)$ \\
\hline Congo & 14 & $(18.2)$ \\
\hline Bhutan & 7 & $(9.0)$ \\
\hline Afghanistan & 5 & $(6.5)$ \\
\hline Somalia & 5 & $(6.5)$ \\
\hline Other Countries & 12 & $(15.6)$ \\
\hline
\end{tabular}

\section{Procedures}

Participants were administered the RHS-15 by behavioral health providers and refugee health navigators for clinical purposes. The site of the study was an integrated care clinic that provides medical and behavioral health care for refugees in a metropolitan area in the Western United States. Behavioral health providers collected baseline data by administering the RHS-15 as part of the initial health screening that all newly arrived refugees are required to complete upon arrival. Participants were later contacted by refugee health navigators in person or by phone to complete the RHS-15 12 months after the initial screening. A training session was held for refugee health navigators to ensure fidelity and standardization. The refugee health navigators spoke the native language of most participants, and used a phone interpretation system when needed. Additional questions to measure contextual barriers were administered during the 12-month follow-up assessment. All procedures were approved by the Institutional Review Board and all participation was voluntary.

\section{Measures}

Psychological distress. The Refugee Health Screener-15 (RHS-15) [36] is a two part, 15-item instrument used to measure psychological distress among refugees. This measure is intended for use among newly arrived refugees in public health settings, and was normed and validated on the specific populations primarily served at site of this study (i.e., Bhutanese, Burmese, Karen, Iraqi, and Somali refugees). The first part of the instrument consists of 14 items pertaining to participants' self-report on the degree to which psychological health symptoms have been bothersome for the past 30 days. Sample items include "feeling hopeless" and "suddenly scared for no reason." Items are scored on a 5-point Likert-type scale, 0 (not at all) to 4 (extremely). The second part of the instrument is a Distress Thermometer that requires participants to rate the level of distress experienced in the past week on a scale from 0 (no distress) to 10 (extreme distress). A positive psychological distress score is determined by a score of $\geq 12$ on items 1-14, and/or a score of $\geq 5$ on the Distress Thermometer. Research evaluating the RHS-15 showed good specificity (.86 to .89 ), and good sensitivity (.81 to .95). Cronbach's alpha for the full scale, the 14-item score, and the Distress Thermometer ranged from .951 to .960 , indicating high reliability [36]. When compared with other diagnostic instruments (e.g., the Harvard Trauma Questionnaire and the Hopkins Symptom Checklist), the case sensitivity and specificity was acceptable $(>0.87 / 0.77)$.

\section{Contextual Factors}

In order to ensure cultural relevance and sensitivity, a focus group was conducted with refugee health navigators to determine measurement of contextual factors. The 21-item Post Migration Living Difficulties (PMLD) measure, a tool used to assess typical adversities associated with refugee resettlement, was utilized to facilitate the selection of contextual factor items [37]. Four items from the scale were identified as most relevant for the population included in the current study, given that time constraint was recognized as a significant perceived barrier for refugee participants' completion of the follow-up surveys. Participants responded 1 (yes) or 2 (no) to three items to measure employment, family separation, and local family support: (1) “Are you employed?” (2) "Do you have family members living in your country of origin or in the refugee camp?" and (3) "Do you have family located near you?" English language proficiency was measured through a single item, "How comfortable are you with communicating in English?" and was rated on a 3-point scale: 1 (not at all), 2 (somewhat), 3 (very).

Behavioral health treatment. The number of behavioral health sessions completed by participants was recorded for those who opted into short term behavioral health treatment at the integrated care clinic. 


\section{Data Analyses}

Data was assessed on two time points: baseline and 12-month follow-up. Psychological distress was assessed with both the 14-item scale and the Distress Thermometer. Data was scaled such that higher values indicated greater levels of psychological distress. Several one-way repeated measures ANOVAs were constructed to test the four hypotheses. Models were built to test the interaction between each of the contextual factors and time with psychological distress at baseline and 12-months. The contextual factors for each model included: employment, English language proficiency, family separation, and local family support. Number of behavioral health sessions was used as a covariate. Models were run separately for each of the two outcomes of the psychological distress scale: change in the 14-item scale and change in the Distress Thermometer on the RHS-15. In order to understand how much variance was accounted for between independent and outcome variables, partial eta squared was also calculated.

\section{Results}

\section{Descriptive Statistics}

There were no differences observed with psychological distress for gender or among countries of origin. Table 3 represents the means and standard deviations for the RHS-15 at both baseline and at the 12-month follow up. The means of both the 14-item scale (p, 0.001) and Distress Thermometer $(\mathrm{p}=0.025)$ of psychological distress decreased significantly over time.

Table 3. Mean and Standard Deviation (SD) of Refugee Health Screener

\begin{tabular}{|c|c|c|}
\hline \multirow{2}{*}{ Refugee Health Screener } & Baseline & Follow up \\
\cline { 2 - 3 } & $M(S D)$ & $M(S D)$ \\
\hline Items 1-14 & $16.77(10.75)$ & $12.59(12.33)$ \\
\hline Distress Thermometer & $5.12(2.18)$ & $4.25(2.78)$ \\
\hline
\end{tabular}

\section{Contextual Factors and Psychological Distress}

Repeated measures ANOVAs were used to address the first hypothesis predicting a significant main effect of employment on psychological distress. Results showed that the model was marginally significant for the 14-item scale, $F(1,71)=3.94, p=.051, \eta_{\mathrm{p}}{ }^{2}=.053$, but not significant for the model using the Distress Thermometer. Those individuals who reported not being employed at the 12-month reassessment also reported lower reductions in distress, compared to those reporting being employed (see Tables 4 and 5 for changes in mean).

One-way repeated measures ANOVAs were used to test the second hypothesis of the main effect of English language proficiency on psychological distress. The 14-item model showed no statistical significance. However, there was a statistically significance main effect of English language proficiency on psychological distress for the distress thermometer, $F(1,71)=4.95, p=.03, \eta_{\mathrm{p}}{ }^{2}=.085$. Participants who at the 12-month reassessment endorsed some or high English proficiency also reported greater reductions in distress, as measured by the Distress Thermometer item (see Tables 4 and 5).

Table 4. Mean, Standard Deviation, and Change in Contextual Factors from Baseline to Follow Up for Items 1-14 of RHS-15

\begin{tabular}{|c|c|c|c|c|}
\hline Variables & Response & Baseline & $\begin{array}{c}\text { Follow } \\
\text { up }\end{array}$ & Change \\
\hline Employment status & no & 18.31 & 13.31 & -5.00 \\
\hline Employment status & yes & 15.64 & 12.01 & -3.63 \\
\hline $\begin{array}{c}\text { English language } \\
\text { proficiency }\end{array}$ & not at all & 20.96 & 17.77 & -3.21 \\
\hline $\begin{array}{c}\text { English language } \\
\text { proficiency }\end{array}$ & somewhat & 14.96 & 9.87 & -5.09 \\
\hline $\begin{array}{c}\text { English language } \\
\text { proficiency }\end{array}$ & very & 15.48 & 12.00 & -3.48 \\
\hline $\begin{array}{c}\text { Family living near } \\
\text { Family living near }\end{array}$ & no & 20.14 & 16.41 & -3.73 \\
\hline $\begin{array}{c}\text { Family living in } \\
\text { R/COO }\end{array}$ & no & 21.22 & 22.11 & 0.89 \\
\hline $\begin{array}{c}\text { Family living in } \\
\text { R/COO }\end{array}$ & yes & 14.92 & 8.63 & -6.29 \\
\hline \multicolumn{2}{|c|}{} & & & -4.38 \\
\hline
\end{tabular}

Table 5. Mean, Standard Deviation, and Change in Contextual Factors from Baseline to Follow Up for Distress Thermometer of RHS-15

\begin{tabular}{|c|c|c|c|c|}
\hline Variables & Response & Baseline & $\begin{array}{c}\text { Follow } \\
\text { up }\end{array}$ & Change \\
\hline Employment status & no & 4.67 & 4.21 & -0.46 \\
\hline Employment status & yes & 5.45 & 4.28 & -1.17 \\
\hline $\begin{array}{c}\text { English language } \\
\text { proficiency }\end{array}$ & not at all & 4.85 & 5.04 & 0.19 \\
\hline $\begin{array}{c}\text { English language } \\
\text { proficiency }\end{array}$ & somewhat & 5.42 & 4.00 & -1.42 \\
\hline $\begin{array}{c}\text { English language } \\
\text { proficiency }\end{array}$ & very & 4.81 & 3.81 & -1.00 \\
\hline $\begin{array}{c}\text { Family living near } \\
\text { Family living near }\end{array}$ & no & 4.95 & 5.24 & 0.29 \\
\hline $\begin{array}{c}\text { Family living in } \\
\text { R/COO }\end{array}$ & no & 4.96 & 5.37 & 0.41 \\
\hline $\begin{array}{c}\text { Family living in } \\
\text { R/COO }\end{array}$ & yes & 5.19 & 3.79 & -1.40 \\
\hline
\end{tabular}

For the third hypothesis, several one-way repeated measures ANOVAs were conducted to test the effect of family separation on psychological distress. In both the 14-item scale and distress thermometer models, there was a significant main effect of family living in country of origin or refugee camp on psychological distress over time. Results from the 14-item scale model was $F(1,71)=11.84$, $p=.001, \eta_{\mathrm{p}}{ }^{2}=.143$, and the Distress Thermometer model, $F(1,71)=9.41, p=.003, \eta_{\mathrm{p}}{ }^{2}=.117$. Psychological distress was lower at the 12-month follow-up for those individuals that reported having family in a refugee camp or country of origin (see Tables 4 and 5).

For the fourth hypothesis, stating that psychological distress would decrease at follow up for those who have 
family members residing locally, several one-way repeated measures ANOVAs were conducted to test the effect of family support on psychological distress. Results from both the 14-item scale and Distress Thermometer showed no significant effect of family living near on psychological distress.

\section{Discussion}

The primary purpose of the present study was to examine the influences of contextual factors, including employment, host country language proficiency, separation from family, and local family support, on psychological distress for newly arrived refugees over one year.

Current study results supported the first hypothesis, predicting that employment would increase psychological distress. Findings also supported the second hypothesis, predicting that English language proficiency would decrease psychological distress. The third hypothesis, predicting that family separation would increase psychological distress, was not supported by study findings. The fourth hypothesis, predicting that local family support would decrease psychological distress, was also not supported by current study results. Overall, results partially aligned with previous research exploring connections between contextual variables and distress for refugees, and further exploration is warranted. Findings gleaned from the current study provide valuable information to better inform use of available resources, direction for future research with refugee populations, and insight into risk and protective factors for practicing public health professionals working with refugees.

As predicted in the first hypothesis, employment was found to significantly increase psychological distress for resettled refugees after one year. This finding aligns with results from a recent study conducted by Guajardo and colleagues [33] examining mental health distress among Iraqi refugees in Australia. Specifically, refugees with longer periods of resettlement were more distressed than those recently arrived. The authors suggested that a lack of effective resettlement services, including employment support, may contribute to increased distress. Research examining the interaction of employment and mental health outcomes with other vulnerable populations, such as low income women who struggle to find childcare in the United States [38], low education individuals in Brazil [39], and racial minorities in Canada [40] also demonstrated that non-professional employment or under employment results in psychological distress. Other scholars posit that refugees resettled for longer periods may experience employment as a barrier due to a concurrent decrease in social program funding $[24,34]$. Further, inadequate employment can cultivate a new set of stressors, such as childcare issues, experiencing inequality at work due to a language barrier, and significant transportation problems related to long and difficult commutes [41]. For refugees arriving with a prior vocation, such as those granted with a Special Immigrant Visa (i.e., refugees that experience persecution because of employment with the United States government in their country of origin, such as those arriving from Iraq and Afghanistan), it is conceivable that being unable to continue working in their trained field and accepting an underpaid, unskilled job out of necessity would contribute to poor psychological health.

Proficiency of at least some English language skills significantly decreased psychological distress for recently arrived refugees over one year, supporting the second hypothesis. This result is comparable to prior findings that reflect the connection between poor English language skills and distress among refugees [3, 23, 32]. The ability to communicate in the primary language of the host country reduces contextual barriers that, in turn, contribute to reductions in psychological distress [7]. In a broader ecological context, possessing some host country language skills allows refugees to understand and potentially have some influence on their surrounding micro-, meso-, and exosystems [25]. For example, the ability to communicate in their host country allows refugees to develop relationships with host country community members, navigate new surroundings, be more competitive job applicants, and participate in larger conversations that may influence a refugee family's sense of safety and belongingness.

The most interesting findings resulted from the examination of the third and fourth hypotheses. Family support, as measured by members living nearby, did not reveal any significant observations. Family separation, however, as measured by family members remaining in or near participants' country of origin, significantly decreased psychological distress over one year instead of increasing over time as expected. These findings were contrary to previous research suggesting that having family support significantly decreased psychological distress [7], and that worrying about family in the country of origin made a unique contribution to depression, anxiety, and somatic related mental health symptoms [32]. Two plausible explanations for these findings include the use of single item measurement and the length of time between the two assessments.

First, local family support and family separation were each assessed using only one item, and may not have captured other aspects of family separation contributing to psychological distress. Additional items such as the relationship status of the separated family members to the participants (e.g., spouse, parent, or distant relative) and the perceived level of safety in the separated family member's environment could have helped to explain why those who had family in their country of origin or refugee camp experienced decreased levels of psychological distress. It also is possible that recently arrived refugees have developed additional supportive relationships with 
other neighbors and community members, and that having local family connections is not as significant after one year as it may be as upon arrival. Similarly, separated family members may be in the process of immigrating to the United States to be reunited with the participant after one year, alleviating concerns and decreasing distress.

Second, given that the follow-up assessment was collected after one year, the impact of family separation on psychological distress could be non-linear $[9,10]$ and may not have been captured with only a 12 month follow-up assessment. The time between assessments, in other words, may have been too large to accurately account for the relationship between family separation and psychological distress as well as family support and psychological distress.

\section{Limitations and Future Directions}

Findings should be considered in light of limitations. First, the utilization of single items to capture contextual factors limited the ability to fully understand the impact of these variables on psychological distress, and to explain unexpected results. Second, increasing the sample size to in turn increase statistical power and allow for observation of within study comparisons would expose differences in psychological distress among cultural groups. Third, given that psychological distress may fluctuate over time, it may have been more useful to assess the effects of the various contextual factors over multiple time points (e.g., at three or six month intervals) to ascertain how distress changes longitudinally. Finally, the sampling method utilized limits the generalizability of study findings, given that follow up data was limited to only participants who initially endorsed psychological distress upon arrival.

Despite these limitations, the current study uniquely contributes to refugee literature, and findings call attention to several important research and practice implications. Given that the study was grounded in the ecological model, ecological validity and community utility were increased by the use of culturally matched patient navigators informing contextual factor measurement. Other study contributions include the cultural diversity within the study sample [20] and use of the RHS-15 to avoid Western-bound conceptualization of mental health [22]. With regard to research, larger sample sizes would greatly increase the ability to observe trends and better understand the effects of contextual factors fluctuating over time. In addition, future studies should consider utilization of multi-item subscales to better capture contextual factors, such as local living conditions, access to resources, and the ability to send money home. Inclusion of non-distressed refugees in the study sample is another important step forward, in order to be able to compare results with a normative refugee population. Lastly, utilizing a mixed method design could enrich quantitative findings and allow for greater understanding of the complexity involved when examining this population.

Study results indicate that public health practitioners can better assist recently arrived refugees by prioritizing resources toward supporting advanced vocational options, increasing access to host country language courses, and facilitating connections to family members in their home countries to improve psychological well-being. First, given that current findings suggest increased distress upon initial employment, public health professionals may more effectively help newly resettled refugees by regularly exploring issues related to employment and providing resources to further pursue vocational aspirations. Such support can foster employment success and empower refugees to maintain economic stability within the local community. Second, while acquiring employment quickly can temporarily relieve the pressure of needing to pay for the many living expenses that refugee families are often unaccustomed to, long work hours and difficult commutes often make it unfeasible to also engage in English classes. Increasing access to host country language classes across weekends, evenings, and with childcare available can help address these barriers, and in turn, improve psychological health and well-being for recently arrived refugees. Finally, because connection to family members remaining in or near their country of origin appears to decrease psychological distress over time for recently resettled refugees, supporting this connection by ensuring newly resettled refugees are aware of available resources to assist with family reunion and ways to maintain contact with family members abroad may be beneficial.

The current study responds to the call for research to explore the relationship between post-migration psychosocial factors and long term mental health outcomes for refugees. While this study included some unexpected findings, the utilization of a larger and more diverse sample that is assessed over time contributes to the continued the process of understanding the effects of contextual factors on psychological distress.

\section{Acknowledgements}

A preliminary version of this article was presented at the American Psychological Association held in Denver, Colorado, on August $5^{\text {th }}, 2016$. This research did not receive any specific grant from funding agencies in the public, commercial, or not-for-profit sectors. No conflicts of interest have been declared. Permission to use the Refugee Health Screener was granted by the developer, Michael Hollifield, M.D., per submission of the Utilization Agreement. The authors gratefully acknowledge Dr. Jan Jenkins, the director of the Colorado Refugee Wellness Center (CoRWC), and the additional contributors include staff members, trainees, and volunteers affiliated with the CoRWC: Lawahiz Abbas, Fouzia Abdi, Enas Alsharea, 
Bhanu Bhattarai, Dim Cing, Darien Combs, Amanda Doll, Hari Gautam, Henriette Habimana, Lindsey Harcus, Winnie Hunter, Adaobi Iheduru, Adnan Jabar, Melissa Marquez, Cristine Muduva, Katherine Redd, Shaimaa Saleem, Shane Spears, Khin Than, and Emma Williams.

\section{REFERENCES}

[1] United Nations High Commissioner for Refugees (2016). Resettlement. Retrieved from http://www.unhcr.org/en-us/resettlement.html

[2] Murray, K. E., Davidson, G. R., \& Schweitzer, R. D. (2010). Review of refugee mental health interventions following resettlement: Best practices and recommendations. American Journal of Orthopsychiatry, 80(4), 576-585. doi: 10.1111/j.1939-0025.2010.01062.x

[3] Bentley, J. A., Thoburn, J. W., Stewart, D. G., \& Boynton, L. D. (2012). Post-migration stress as a moderator between traumatic exposure and self-reported mental health symptoms in a sample of Somali refugees. Journal of Loss and Trauma, 17(5), 452-469. doi: 10.1080/15325024.2012. 665008

[4] Keller, A., Lhewa, D., Rosenfeld, B., Sachs, E., Aladjein, A., Cohen, I., ...\& Porterfield, K. (2006). Traumatic experiences and psychological distress in an urban refugee population seeking treatment services. Journal of Nervous and Mental Disease, 194, 188-194. doi: 10.1097/01.nmd.0000202494.7 5723.83

[5] Porter, M., \& Haslam, N. (2005). Predisplacement and postdisplacement factors associated with mental health of refugees and internally displaced persons: A meta-analysis. Journal of the American Medical Association, 294, 602-612. doi: 10.1001/jama.294.5.602

[6] Turner, S. W., Bowie, C.., Dunn, G., Shapo, L., \& Yule, W. (2003). Mental health of Kosovan Albanian refugees in the UK. British Journal of Psychiatry, 182, 444-448. doi: 10.1192/bjp.182.5.444

[7] Goodkind, J. R., Hess, J. M., Isakson, B., LaNoue, M., Githinji, A., Roche, N., . . \& \& Parker, D. P. (2014). Reducing refugee mental health disparities: A community-based intervention to address postmigration stressors with African adults. Psychological Services, 11(3), 333-346. doi: 10.1037/a0035081

[8] Stenmark, H., Catani, C., Neuner, F., Elbert, T., \& Holen, A. (2013). Treating PTSD in refugees and asylum seekers within the general health care system. A randomized controlled multicenter study. Behaviour Research and Therapy, 51(10), 641-647. doi: 10.1016/j.brat.2013.07.002

[9] Miller, K. E., Weine, S. M., Ramic, A., Brkic, N., Bjedic, Z. D., Smajkic, A., ... \& Worthington, G. (2002). The relative contribution of war experiences and exile-related stressors to levels of psychological distress among Bosnian refugees. Journal of Traumatic Stress, 15, 377-387. doi: 10.1023/A:1020181124118

[10] Mollica, R. F., Caspi-Yavin, Y., Bollini, P., Truong, T., Tor, S., \& Lavelle, J. (1992). The Harvard trauma questionnaire: validating a cross-cultural instrument for measuring torture, trauma, and post-traumatic stress disorder in Indochinese refugees. Journal of Nervous and Mental Disease, 180, 111116. doi: 10.1097/00005053-199202000-00008

[11] Slobodin, O., \& de Jong, J. T. (2015). Mental health interventions for traumatized asylum seekers and refugees: What do we know about their efficacy? International Journal of Social Psychiatry, 61(1), 17-26. doi: $10.1177 / 0020764014535752$

[12] Daud, A., Skoglund, E., \& Rydelius, P. (2005). Children in families of torture victims: Transgenerational transmission of parents' traumatic experiences to their children. International Journal of Social Welfare, 14, 23-32. doi:10.1111/j.1468-2397.2005.00336.x

[13] Lien, L., Oppedal, B., Haavet, O. R., Hauff, E., Thoresen, M., \& Bjertness E. (2006). Own and parental war experience as a risk factor for mental health problems among adolescents with an immigrant background: Results from a cross sectional study in Oslo, Norway. Clinical Practice and Epidemiology in Mental Health, 2(30), 1-8.

[14] Gerritsen, A. A., Bramsen, I., Devillé, W., Van Willigen, L. H., Hovens, J. E., \& Van Der Ploeg, H. M. (2006). Physical and mental health of Afghan, Iranian and Somali asylum seekers and refugees living in the Netherlands. Social Psychiatry and Psychiatric Epidemiology, 41(1), 18-26. doi: 10.1007/s00127-005-0003-5

[15] Yakushko, O., Backhaus, A., Watson, M., Ngaruiya, K., \& Gonzalez, J. (2008). Career development concerns of recent immigrants and refugees. Journal of Career Development, 34(4), 362-396. doi:10.1177/0894845308316 292

[16] Birman, D., Trickett, E. J., \& Vinokurov, A. (2002). Acculturation and adaptation of Soviet Jewish refugee adolescents: Predictors of adjustment across life domains. American Journal of Community Psychology, 30(5), 585-607. doi: 10.1023/A:1016323213871

[17] Connor, P. (2010). Explaining the refugee gap: Economic outcomes of refugees versus other immigrants. Journal of Refugee Studies, 23, 377-397. doi:10.1093/jrs/feg025

[18] Pumariega, A. J., Rothe, E., \& Pumariega, J. B. (2005). Mental health of immigrants and refugees. Community Mental Health Journal, 41(5), 581-597. doi: 10.1007/s10597-005-6363-1

[19] Bastin, P., Bastard, M., Rossel, L., Melgar, P., Jones, A., \& Antierens, A. (2013). Description and predictive factors of individual outcomes in a refugee camp based mental health intervention (Beirut, Lebanon). Public Library of Science, 8(1). doi:10.1371/journal.pone.0054107

[20] McFarlane, C. A., \& Kaplan, I. (2012). Evidence-based psychological interventions for adult survivors of torture and trauma: a 30-year review. Transcultural psychiatry, 49(3-4), 539-567. doi: 10.1177/1363461512447608

[21] Birman, D., \& Tran, N. (2008). Psychological distress and adjustment of Vietnamese refugees in the United States: Association with pre-and postmigration factors. American Journal of Orthopsychiatry, 78(1), 109. doi: 10.1037/0002-9432.78.1.109

[22] Bogic, M., Njoku, A., \& Priebe, S. (2015). Long-term 
mental health of war-refugees: A systematic literature review. BMC International Health and Human Rights, 15:29. doi: 10.1186/s12914-015-006

[23] Marshall, G. N., Schell, T. L., Elliott, M. N., Berthold, S. M., $\&$ Chun, C. A. (2005). Mental health of Cambodian refugees 2 decades after resettlement in the United States. Journal of the American Medical Association, 294(5), 571-579. doi: 10.1001/jama.294.5.571

[24] Beiser, M., \& Hou, F. (2001). Language acquisition, unemployment and depressive disorder among Southeast Asian refugees: A 10-year study. Social Science \& Medicine, 53(10), 1321-1334. doi: 10.1037/cap0000064

[25] Chronister, K. M., McWhirter, B., and Kerewsky, S. (2004). Counseling and ecological prevention practice. In R. K. Coyne \& E. P. Cook (Eds.), Ecological counseling: An innovative approach to conceptualizing person-environment interaction (315-338). Alexandria, VA: American Counseling Association.

[26] Harvey, M. R. (2008). Towards an ecological understanding of resilience in trauma survivors. Journal of Aggression, Maltreatment, \& Trauma, 14, 9-32. doi:10.1300/J146v14n0 1_02

[27] Bronfenbrenner, U. (1979). The ecology of human development. Cambridge, MA: Harvard University Press.

[28] Elbedor, S., Bensel, R., \& Bastian, D. T. (1993). Ecological integrated model of children of war: Individual and social psychology. Child Abuse \& Neglect, 17, 805-819. doi:10.1016/S0145-2134(08)80011-7

[29] Fazel, M., Reed, R. V., \& Panter-Brick, C. (2012). Mental health of displaced and refugee children resettled in high income countries: Risk and protective factors. The Lancet, 379, 266-282. doi: 10.1016/S0140-6736(11)60051-2

[30] George, M. (2012). Migration traumatic experiences and refugee distress: Implications for social work practice. Clinical Social Work Journal, 40, 429-437. doi:10.1007/a10615.012-0397-y

[31] Miller, K. E., \& Rasmussen, A. (2010). War exposure, daily stressors, and mental health in conflict and post-conflict settings: bridging the divide between trauma-focused and psychosocial frameworks. Social Science \& Medicine, 70(1), 7-16. doi: 10.1016/j.socscimed.2009.09.029

[32] Schweitzer, R. D., Brough, M., Vromans, L., \& Asic-Kobe, M. (2011). Mental health of newly arrived Burmese refugees in Australia: Contributions of pre-migration and post-migration experience. Australian and New Zealand Journal of Psychiatry, 45(4), 299-307. doi:

\section{$10.3109 / 00048674.2010 .543412$}

[33] Guajardo, M. G. U., Slewa-Younan, S., Smith, M., Eagar, S., \& Stone, G. (2016). Psychological distress is influenced by length of stay in resettled Iraqi refugees in Australia. International Journal of Mental Health Systems, 10(1), 4. doi: 10.1186/s13033-016-0036-Z

[34] Westermeyer, J. (1989). Mental health for refugees and other migrants: Social and preventive approaches. Springfield, Illinois: Charles C. Thomas Publisher.

[35] Ryan, D. A., Benson, C., \& Dooley, B. A. (2008). Psychological distress and the asylum process: A longitudinal study of forced migrants in Ireland. Journal of Nervous \& Mental Disease, 196, 37-45. doi:10.1097/NMD.00013e31815fa51c

[36] Hollifield, M., Verbillis-Kolp, S., Farmer, B., Toolson, E. C., Woldehaimanot, T., Yamazaki, J., . . \& \& SooHoo, J. (2013). The Refugee Health Screener-15 (RHS-15): development and validation of an instrument for anxiety, depression, and PTSD in refugees. General Hospital Psychiatry, 35(2), 202-209. doi: 10.1016/j.genhosppsych.2012.12.002

[37] Silove, D., Sinnerbrink, I., Field, A., Manicavasagar, V., \& Steel, Z. (1997). Anxiety, depression and PTSD in asylum-seekers: Associations with pre-migration trauma and post-migration stressors. The British Journal of Psychiatry, 170(4), 351-357. doi: 10.1192/bjp.170.4.351

[38] Jacobs, A. W., Hill, T. D., Tope, D., \& O'Brien, L. K. (2016). Employment transitions, child care conflict, and the mental health of low-income urban women with children. Women's Health Issues, 26(4), 366-376. doi: 10.1016/j.whi.2016.05.003

[39] Lopes, C. S., Araya, R., Werneck, G. L., Chor, D., \& Faerstein, E. (2010). Job strain and other work conditions: Relationships with psychological distress among civil servants in Rio de Janeiro, Brazil. Social Psychiatry and Psychiatric Epidemiology, 45(3), 345-354. doi: 10.1007/s00127-009-0066-9

[40] Premji, S. \& Shakya, Y. (2017). Pathways between under/unemployment and health among racialized immigrant women in Toronto. Ethnicity \& Health, 22(1), 17-35. doi: 10.1080/13557858.2016.1180347

[41] Hernandez, D. J., Denton, N. A., \& Macartney, S. E. (2008). Children in immigrant families: Looking to America's future. Social Policy Report: Giving Child and Youth Development Knowledge Away, 22(3). New York: Department of Sociology \& Center for Social and Demographic Analysis, New York University at Albany. 